\title{
Economic analysis of wind power consumption promoted by regenerative electric heating with high proportion of renewable energy
}

\author{
Wang Zhenyu ${ }^{1,2 *}$, Zhang Jianhua ${ }^{3}$, Shao Chong $^{3}$, Xu Lanlan ${ }^{3}$, Han Yongjun ${ }^{3}$ \\ ${ }^{1}$ NARI GROUP CORPORATION/STATE GRID ELECTRIC POWER RESEARCH INSTITUTE, Nanjing 210000, China; \\ ${ }^{2}$ STATE GRID ELECTRIC POWER RESEARCH INSTITUTE WUHAN EFFICIENCY EVALUATION COMPANY LIMITED, \\ Wuhan 430074, China \\ ${ }^{3}$ State Grid Gansu Electric Power Company
}

\begin{abstract}
With the rapid development of wind power, the randomness and volatility of wind power have also caused severe problems of wind power consumption. The phenomenon of wind abandonment is particularly prominent in the "three north" areas. The environmental protection and controllability of regenerative electric heating provide a way for wind absorption and abandonment. Therefore, this paper proposes a model to promote wind power consumption by using regenerative electric heating. Firstly, the principle and advantages of the heat storage electric heating equipment are described; secondly, the fine modeling of regenerative electric heating is carried out; then, the mode of using regenerative electric heating to promote wind power consumption is designed;finally, an example is given to analyze the wind power consumption effect and the revenue of load aggregators. Therefore, it is verified that this mode can effectively promote wind power consumption and reduce wind abandon generation, and provide reference for alleviating wind abandon and power limit problem.
\end{abstract}

\section{Introduction}

Vigorously develop clean energy, environmental improvement made great contribution to society, but also appeared a lot of problems at the same time, the wind randomness and volatility caused serious abandon the wind phenomenon [1], to alleviate abandon the wind problems, national policies, encourage the development of high controllability and good environmental protection heat storage type electric heating given to abandon the wind [2]. In this regard, many scholars have done related research. Literature [3-4] designed a non-interactive distributed electric heating system model to improve the wind power consumption capacity of the system by realizing load awakening according to the difference classification of users' power consumption behavior and using indoor temperature as the regulating lever. Literature [5] puts forward an optimal operation strategy for household regenerative electric heating, which takes temperature utility value and load transfer rate as evaluation indexes for user heating comfort and economy respectively.

The output prediction of regenerative electric heating equipment and the prediction of electric heating load are the key prerequisites for electric heating absorption and wind abandonment. Regarding the prediction method, some scholars have made relevant researches: Literature [6], from the perspective of meteorological factors, proposed the electric heating load prediction method with

\footnotetext{
* Corresponding author: wangzhenyu1@sgepri.sgcc.com.cn
}

temperature factor as the main factor and humidity factor as the correction; Literature [7] proposed a fine modeling method for three types of typical high-power controllable loads on the residential side (HVAC system, electric water heater and $\mathrm{EV}$ charging load).

Electric heating participates in dispatching economic analysis. Literature [8-9] analyzed the realization process of economic value in three modes of direct transaction between users of regenerative electric heating and clean energy enterprises, participation in auxiliary service market and spot market. Literature [10] starts from absorbing the participants of wind and light abandonment, establishes a multi-participation economic cost analysis model, and conducts economic analysis on the participants.

Along with our country electric power market matures, regenerative electric heating electricity time have certain selectivity, electricity price when there is a big difference, especially in different time different run time result in system operation cost differences, based on the characteristics of the flexible operation mode, involved in wind power heating deal, can enjoy low price, reduce the running cost of electric heating system, This improves the economy of the whole system. Based on the principle of absorbing and abandoning wind in solid regenerative electric heating, this paper studies its trading mode of participating in wind power heating under load aggregator mode. 


\section{Characteristics and operation principle of regenerative electric heating}

Electric heating system completely rely on the power, in the process does not produce carbon emissions or pollution, it has the advantages of zero emission, no pollution, and distributed electric heating mode compared with the centralized electric heating is more easy to control, the user interface more friendly, heating system can be based on room temperature automatic control and user individuality, further improve the system efficiency. In addition, the electric heating system is usually directly connected to the user's residence, and there is no need for a large number of heat pipes between the heat and power plant and the user, thus reducing the investment and floor space of heat pipes and further reducing the user's heating cost.

Regenerative electric heating is to increase energy storage technology in the electric heating system, the heat storage technology according to different storage heat carrier in China, divided into heat and heat storage of solid materials, water thermal storage and heat storage area smaller, specific heat of solid materials, high temperature resistant, the regenerative temperature up to $800{ }^{\circ} \mathrm{C}$, is a more ideal way of accumulation of heat, so this article is based on solid type thermal storage heating works, Study its ability to absorb and abandon wind.

Its operating principle is that users set the heat storage power, peak and valley time and heating temperature through the controller according to their own demands and electricity price policies. The controller starts and stops the heating element according to the time period and the temperature of the heat accumulator, and controls the heat emission by setting the heat release power, so as to maintain the indoor temperature within the required range. In order to promote wind abandonment absorption and reduce heating costs, users can heat storage with high power while heating in the peak section of wind abandonment, and stop heat storage in the valley section of wind abandonment, and heat storage is mainly provided by heat storage body.

\section{Refined modeling of regenerative electric heating system}

Electric heating load prediction model:

$$
P=P_{B}+P_{W}
$$

In the formula, $\mathrm{P}$ is the total demand of electric heating load, $\mathrm{P}_{\mathrm{B}}$ is the load component of basic electric heating, and $\mathrm{P}_{\mathrm{W}}$ is the load component of electric heating sensitive to meteorological factors.

$$
P_{B}(t)=\left[\sum_{t=1}^{24}\left(C_{\text {air }} \rho_{\text {air }} N S H+\partial K A\right)\left(T_{\text {in }}(t)-T_{\text {out }}(t)\right)-Q_{\text {ine }}-Q_{\text {inh }}\right] / \eta_{h}(2)
$$

Where, $C_{\text {air }}$ is the specific heat capacity of air; $\rho_{\text {air }}$ is air density; $\mathrm{N}$ is the number of air exchange; $\mathrm{S}$ is housing area; $\mathrm{H}$ is the indoor height of the house; $\mathrm{Q}_{\text {ine }}$ is the heat of electrical equipment; $Q_{\text {inh }}$ is the body heat; $\partial$ is the temperature difference correction coefficient of the envelope; $\mathrm{K}$ is the heat transfer coefficient of the envelope; $\mathrm{A}$ is the area of the enclosure structure; $\mathrm{T}_{\mathrm{in}(\mathrm{t})}$ is the indoor temperature at $\mathrm{t} ; \mathrm{T}_{\text {out }(\mathrm{t})}$ is the outdoor temperature at $\mathrm{t} ; \eta_{\mathrm{h}}$ is the efficiency of electricity to heat.

In order to improve the accuracy of electric heating load prediction, considering the influence of humidity on electric heating load, regression analysis method was adopted to correct the electric heating load prediction, and the formula was obtained:

$$
P_{W}=\max \left(\frac{\Delta S_{H}}{23.10}, \frac{\Delta S_{T}}{39.43}\right) / \min \left(\frac{\Delta S_{H}}{23.10}, \frac{\Delta S_{T}}{39.43}\right)
$$

In the formula: $\Delta \mathrm{S}_{\mathrm{H}}$ is the sensitivity of electric heating load at corresponding humidity $\mathrm{H}$, and $\Delta \mathrm{S}_{\mathrm{T}}$ is the sensitivity of electric heating load at corresponding temperature $\mathrm{T}$.

Output model of regenerative electric heating equipment:

$$
Q_{h}(t)=\eta_{h} \times P_{h}(t)
$$

In the formula, $\mathrm{P}_{\mathrm{h}}(\mathrm{t})$ is the electricity consumed by the heating of the regenerative electric heating equipment. The conversion efficiency of solid regenerative electric heating is usually $95-98 \%$, which is calculated as $95 \%$ in this paper.

Solid heat storage materials used in solid heat storage electric heating equipment are mostly $\mathrm{MgO}_{\mathrm{g}}$. The temperature can be heated to $800^{\circ} \mathrm{C}$, which can continue to heat houses for a long time. The relationship between heat storage and temperature is as follows:.

$$
S_{\text {in }}=\mathrm{cm}\left(T_{2}-T_{1}\right), T_{2} \leq 800^{\circ} \mathrm{C}
$$

Where, $\mathrm{C}$ is the specific heat capacity of $\mathrm{M}_{\mathrm{g}} \mathrm{O} ; \mathrm{m}$ is the mass of $\mathrm{MgO}_{\mathrm{g}} \mathrm{T}_{1}$ is the temperature before $\mathrm{MgO}$ heat storage; $\mathrm{T}_{2}$ is the temperature of $\mathrm{Mg}_{\mathrm{g}} \mathrm{O}$ after heat storage. Wherein, the relation of heat storage capacity of regenerative electric heating with time is as follows:

$$
\begin{gathered}
S_{H S}(t)=\left(1-\eta_{H S}\right) S_{H S}(t-1)+\left(S_{\text {in }}(t)-S_{\text {out }}(t)\right) \\
S_{\text {in }}(t)=Q_{\text {in }}(t) \eta_{\text {in }} \\
S_{\text {out }}(t)=Q_{\text {out }}(t) \eta_{\text {out }}
\end{gathered}
$$

Where, $\mathrm{S}_{\mathrm{HS}}(\mathrm{t})$ is the heat storage capacity of regenerative electric heating at time $t, \eta_{\mathrm{HS}}$ is the heat storage loss rate, and $\mathrm{S}_{\text {out }(t)}$ is the heat release; $\mathrm{Q}_{\mathrm{in}(\mathrm{t})}$ is the heat storage power at $t, Q_{\text {out }(t)}$ is the heat release power at $t, \eta_{\text {in }} 、 \eta_{\text {out }}$ are the efficiency of heat storage and heat release of the heat storage tank.

\section{The mode and economic analysis of wind power consumption promoted by regenerative electric heating}

\subsection{Regenerative electric heating promotes wind power consumption mode}

The transaction mode of regenerative electric heating participating in wind power consumption mainly includes four subjects, namely, wind power generators, power grid companies, load aggregators and residential users who adopt regenerative electric heating. The transaction mode is that wind power enterprises submit forecast electricity supply to power grid companies through forecast wind 
power quantity every day. Load aggregators by signing a contract to collect the heat storage type electric heating residential heating demand, contract contents include heating prices, participate in wind power enterprise demand response time and economic compensation, etc., and shall submit to the grid forecasting and purchasing power, preferred to use wind power, wind power shortage and other battery energy storage is insufficient to choose to use.

\subsection{Economic evaluation model of regenerative electric heating}

Regenerative electric heating meets the access conditions of "direct power purchase by large users". Through direct negotiation with the wind farm, the abandoned wind power is purchased at the agreed price, and the power grid only charges the transmission and distribution cost, while the rest electricity is purchased from the power grid according to the time-of-use price. The economic evaluation model of regenerative electric heating is shown in Equation (9).

$$
P_{\text {sum }}=C_{\text {jp }} \sum_{i=1}^{n} Q_{\text {hot }}^{i}+C_{\text {hot }} S-P_{\text {pay. s }}-P_{\text {pay. } \mathrm{r}}
$$

Where, $\mathrm{S}$ is the area of regenerative electric heating; $C_{\text {hot }}$. Charge for heating; $C_{\mathrm{jp}}$ is the unit price of energy conservation and emission reduction subsidy; $P_{\text {pay.s }}$ is the static investment cost. The static investment cost mainly refers to the cost of allocating the initial investment cost and decommissioning residual value to the life period N years. $P_{\text {pay.r }}$ is the operation cost, which refers to the cost corresponding to the electricity consumption of the regenerative electric boiler during the whole heating period.

\section{Example simulation}

Taking a clean heating demonstration project as an example to analyze the economy of the heat-storage heating system with abandoned air, the calculation conditions are given as follows.

(1) Heating conditions. The heating period is 181 days; Heating area of $200,000 \mathrm{~m} 2$; Heating price :20.375 yuan/m2; The unit price of energy conservation and emission reduction subsidy is O. (2) Regenerative electric heating system parameters. The regenerative electric heating system consists of 9 electric boilers. Electrothermal conversion efficiency $95 \% ; 5 \%$ heat loss of pipe network; Static investment cost :1 million yuan, N take 20, initial investment cost 22.5 million, residual value 2.5 million; (5) Electricity price agreed with wind farm :0.29535 yuan /kWh; (3) Other parameters. The total installed capacity of wind farm is $400 \mathrm{MW}$; The power transmission and distribution cost of the power grid company is 0.11 yuan $/ \mathrm{kWh}$.

Regenerative electric heating system can be divided into two operating modes: full power heating in trough period, and all-day heating mode with heat storage supply; The economic operation mode during the wind abandoning period is the operation mode when the wind farm is agreed to abandon wind. When the wind abandoning power is insufficient, electricity from the grid is purchased to meet the heating demand.

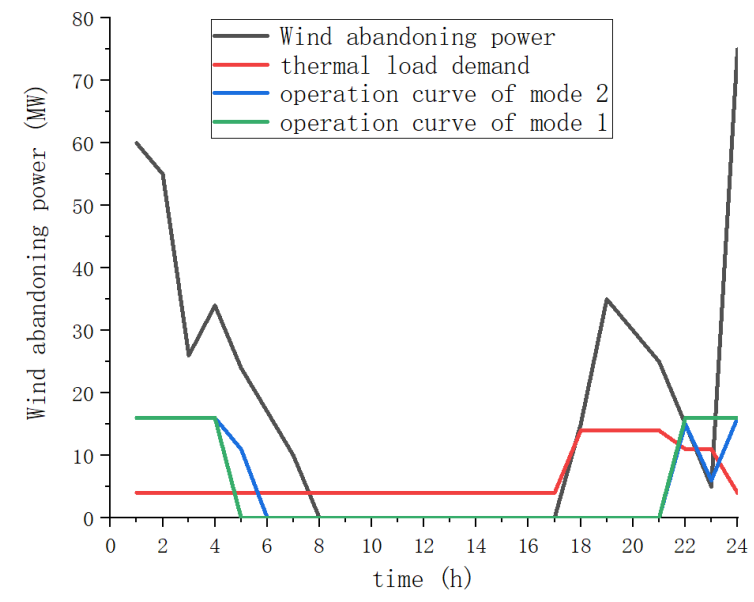

Figure 1. Schematic diagram of operation status of regenerative electric heating system.

Different operation modes of regenerative electric heating system have different amount of absorbed wind and abandoned wind. Due to the uncertainty of wind abandonment itself, wind abandonment in the agreement wind farm fails to meet the heating demand of the regenerative electric heating system. The electricity consumption of regenerative electric heating under the two modes of operation is shown in Table 1.

Table 1. Electricity consumption of regenerative electric heating.

\begin{tabular}{cccc}
\hline $\begin{array}{c}\text { Operation } \\
\text { Mode }\end{array}$ & $\begin{array}{c}\text { Power } \\
\text { Consumption }\end{array}$ & $\begin{array}{c}\text { Wind } \\
\text { Abandoning }\end{array}$ & $\begin{array}{c}\text { Power Grid } \\
\text { Power } \\
\text { Purchase }\end{array}$ \\
\hline Mode 1 & 19796.06 & 4912.07 & $\begin{array}{c}13936.98 \\
\text { (valley) }\end{array}$ \\
& & & $\begin{array}{c}947.01 \\
\text { (flat) }\end{array}$ \\
Mode 2 & 19796.06 & 17574.83 & $\begin{array}{c}2221.23 \\
\text { (valley) }\end{array}$ \\
\hline
\end{tabular}

In the two different modes, the regenerative electric heating system directly buys abandoned wind from the wind farm for heating. See 2 for the economic benefits of the whole heating period. The comprehensive economic losses of the regenerative electric heating in the whole heating period are 4.9493 million yuan and 5.1902 million yuan respectively, mainly due to the high operating electricity price and the lack of corresponding environmental subsidy policies by the government at present. In the electricity market environment, the regenerative electric heating system can further reduce the operation cost and improve the comprehensive income by negotiating with the wind farm to reduce the agreed electricity price of wind abandonment. For Mode 1, the regenerative electric heating system will lose money even if the agreed electricity price of wind abandonment is equal to zero because of the small amount of wind abandonment electricity consumed. For Mode 2, with the 
gradual reduction of electricity price, the regenerative electric heating system gradually turns from loss to profit. When the agreed wind abandonment price is adjusted to 0.014 yuan $/ \mathrm{kW} \mathrm{h}$, the regenerative electric heating system reaches the profit balance point.

Table 2. Economic benefits of heating period under different modes.

\begin{tabular}{ccc}
\hline $\begin{array}{c}\text { Revenue } \\
\text { classification }\end{array}$ & $\begin{array}{c}\text { Mode 1 Revenue } \\
/ 10,000 \text { Yuan }\end{array}$ & $\begin{array}{c}\text { Mode 2 Revenue } \\
/ 10,000 \text { Yuan }\end{array}$ \\
\hline $\begin{array}{c}\text { Heating earnings } \\
\text { Income from } \\
\text { energy conservation } \\
\text { and emission } \\
\text { reduction }\end{array}$ & 407.5 & 407.5 \\
$\quad \begin{array}{c}\text { Static cost of } \\
\text { investment }\end{array}$ & 100 & 0 \\
$\begin{array}{c}\text { Operating costs } \\
\text { Total benefit of } \\
\text { regenerative } \\
\text { electric heating } \\
\text { Income from }\end{array}$ & 826.52 & 100 \\
transmission and \\
distribution of \\
power grid \\
companies
\end{tabular}

The gradual improvement of the power market will make the operation of the regenerative electric heating system fully undertaken by the wind abandonment. When the wind abandonment mode is $100 \%$, the break-even will be achieved when the electricity price is 0.045 yuan $/ \mathrm{kWh}$. With the attention of the country to the problem of fog, the regenerative electric heating will be promoted, the function of energy saving and emission reduction of regenerative electric heating will be subsidized to a certain extent, and its economic benefit will be greatly improved.

\section{Conclusion}

Aiming at the serious problem of wind abandonment in winter heating period in Sanbei area, this paper puts forward a scheme of using regenerative electric heating technology to absorb wind abandonment; The mode of regenerative electric heating to promote wind power consumption is designed; The economic evaluation model of regenerative electric heating system under the background of power market is established; This paper analyzes the impact of the abandoned wind power price on the system economy. The results show that, the use of thermal storage electric heating system can effectively reduce the abandoned wind power of wind farm. The key factors affecting its economy are system operation mode, absorbed abandoned wind power and agreed abandoned wind power price.

\section{Acknowledgments}

This work was supported in part by State Grid Gansu Electric Power Company under 522723120004R

\section{References}

1. DING Tao, SUN Yuge, HE Yuankang, et al. Analysis of the development status and typical cases of clean heating in Northwest China (1) : policy status and existing problems $[\mathrm{J}]$. Proceedings of the CSEE, 2020,40 (15) : 4881-4891.

2. DING Tao, MOU Chenlu, HE Yuankang, et al. Current situation and typical case analysis of clean heating policy in Northwest China (II) : typical case and economic analysis [J]. Proceedings of the CSEE, 2020,40 (16) : 5126-5135.

3. Zhu Jie, Research on Wind Power Consumption Method Based on Controlled Electric Heating Scheme [D]. Harbin, Harbin University of Science and Technology, 2020.

4. ZHAO Tiejun, MENG Qing, WANG Jun, et al. Optimal allocation strategy of photovoltaic and electric heating storage capacity under interactive mode [J]. Journal of Power System and Automation, 2020.

5. CUI Yifeng, LI Zhenguo, YANG Jinqing, et al. Optimal Operation Strategy of Household Regenerative Electric Heating Considering Demand Difference [J]. Automation of Electric Power Systems, 2020.

6. GUO Zhanwu, ZHANG Zeya, ZHOU Xinghua, et al. Research on electric heating load prediction considering meteorological factors $[\mathrm{J}]$. Electrical Measurement \& Instrumentation, 2020.

7. CHEN Zhong, LI Yunqian, LENG Zhaoying, et al. Elaborate modeling and energy management strategy for typical household high-power load [J]. Automation of Electric Power Systems, 2018,42 (22) : 135-143.

8. Li Wei, Zhao Keli, Xu Fei. Mechanism and realization mode of economic value generation of regenerative electric heating regulation capacity $[\mathrm{J}]$. Inner Mongolia Electric Power Technology, 2020,38 (4) : 27-31.

9. LI Qing, ZHOU Ying, LI Dezhi, et al. Research on Economic Evaluation of Wind and Light Abandoning for Distributed Regenerative Electric Heating Based on Quaternary Market [J]. Journal of Guangdong Institute of Petrochemical Technology, 2020,30 (3) : 79-83.

10. ZHU Jing, PAN Fangyuan, et al. Research on Clean Heating Technology and Further Reduction of Electricity Cost -- Based on the Exploration of the Medium and Long Term Trading Mode of Regenerative Electric Heating Load in the Electricity Market [J]. 17. Price Theory \& Practice, 2021. 